\title{
AN OPEN-ENDED DESIGN-BASED LAB EXERCISE FOR A FiRST THERMOFLUIDS COURSE
}

\author{
Michele Hastie* and Jan Haelssig \\ Department of Process Engineering and Applied Science \\ Dalhousie University, Halifax, NS B3H 4R2 \\ *E-mail: michele.hastie@ dal.ca
}

\begin{abstract}
The Thermo-Fluid Engineering I course provides all first-semester second-year engineering students at Dalhousie University with a basic introduction to thermodynamics and fluid mechanics. In the past three years, we have used a combination of six traditional laboratory exercises and a short four-week design project to provide students with hands-on learning experiences in this course. In general, these projects have been wellreceived by students as a welcome break from the many abstract theoretical concepts that are normally associated with introductory thermodynamics. However, two of the continuing challenges with these projects have been the students' limited engineering design experience and the availability of time to perform a design project. To address these challenges, in the fall 2015 offering of Thermo-Fluid Engineering I, the four-week design project was replaced by an open-ended design-based lab exercise.

The open-ended lab exercise required groups of students to develop specific laboratory experiments related to thermodynamics and fluid dynamics, given a limited quantity of resources. While the focus shifted away from a traditional short design project, the openended lab exercise continues to allow students to develop their creative thinking, critical analysis, hands-on, communication, and team work skills, which was the primary purpose of the short design projects in the first place.
\end{abstract}

Keywords: Thermodynamics, Fluid Mechanics, Openended Lab Exercise, Lab-based Learning.

\section{INTRODUCTION}

At Dalhousie University, all second-year engineering students (chemical, civil, electrical, environmental, industrial, materials, mechanical, and mineral resource engineering) take a common introductory course covering the basic principles of thermodynamics and fluid mechanics in a unified manner. The course, Thermo-Fluid
Engineering I, was first offered in the fall semester of 2011 and covers a wide range of topics including fluid statics, thermodynamic properties of fluids, applications of the first and second law to closed and open systems, and engineering applications of the Bernoulli equation. Additionally, students perform six laboratory experiments and, since 2012, a short design project.

It is common practice to incorporate lab experiments into introductory courses. The benefits of lab-based learning include developing students' experimental skills and their ability to work in teams and communicate effectively. Students also learn from making mistakes and taking responsibility for their results $[1,2]$. However, structured lab exercises have the potential to lack the opportunity for students to practice critical and/or creative thinking [3]. This is one of the reasons why we initially introduced the short design project into the thermofluids course. Other benefits of the short design projects included more engagement of active learners and an opportunity to have students gain experience using basic hand tools. A summary of our experiences implementing these short design projects was presented at the Canadian Engineering Education Association (CEEA) conference in 2015 [4].

The major challenges associated with these design projects were the limited design experience of the students, the large class size, and the increased workload on the students. To address these concerns, the format of the project was changed in the fall 2015 offering of the course. Instead of a formal design project, the students, working in a group of 5 or 6 , were asked to develop a new lab experiment for the course. The benefits of projectbased lab exercises over traditional lab experiments are similar to those provided by the short design project, and include increased motivation from the students, more emphasis on creativity and critical thinking, and increased understanding of theoretical knowledge [5].

Although changing from a short design project to an open-ended lab exercise may appear to be a major change, it can be argued that the students are still employing most of the same elements of the design process when 
completing the lab exercise. Developing an experiment requires planning, creativity, and validation - actions that are consistent with the basic design process. Further, considering that the Dalhousie engineering curriculum requires all second-year second-semester students to take a full engineering design course, this change does not significantly reduce the exposure of our students to the entire design process.

For the open-ended lab project, each group of students was assigned one of three lab experiments, and the necessary materials were provided. The groups were asked to assemble the materials, produce a lab procedure, perform their proposed experiment, analyze the data, and present a discussion of the results with suggested improvements.

In contrast to the previous design projects, the suggested experiments were more easily scaled down to two or three lab sessions as opposed to the four lab sessions required by the design projects. This greatly reduced the students' end-of-semester stress.

\section{PROJECT STRUCTURE AND EXPERIMENT DESCRIPTIONS}

\subsection{Project Structure}

The project spanned over two or three 2-hour lab sessions. During the first lab session, the students were provided with the materials necessary to construct and conduct the experiment. This session was also used by the groups to plan and discuss ideas. The students were advised to perform preliminary calculations before the next lab session to make predictions and gain a feel for the physical limitations of the lab equipment. They were expected to come prepared to the second session to start testing. If the groups were well-organized and prepared, they were typically able to collect enough data in this session to produce the final report. Attendance at the third lab session was optional, but students could use this session to repeat the experiment to confirm their results or make changes to their procedure. Approximately half of the class took advantage of the extra lab session, whereas the rest felt confident in the data they collected during the previous session.

Brief descriptions of the three lab experiments are provided below, along with a list of the main components required to build the apparatuses.

\subsection{Friction Losses}

The friction created when a fluid flows through pipes and fittings results in energy being lost by the fluid. For steady flow, the kinetic energy must remain constant to satisfy the continuity equation. Therefore, a decrease in pressure is observed. If the pressure difference between two points can be measured, it can be related to the amount of friction that was experienced by the fluid as it flowed between these two points.

An example of an experimental setup used to measure the friction loss in a straight pipe length is shown in Fig. 1 .

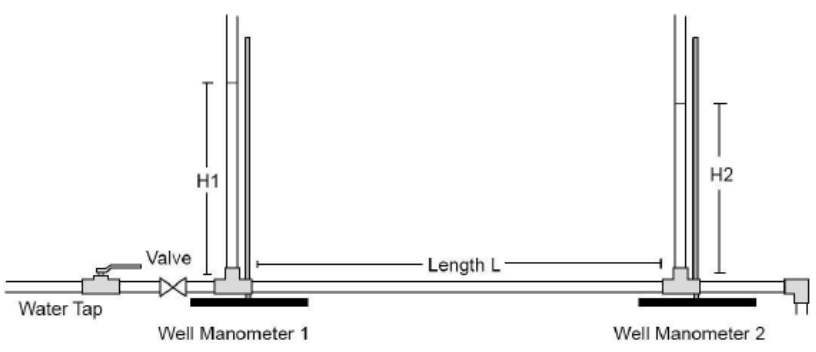

Fig. 1. Friction losses experiment (drawing created by one of the student groups).

Water was supplied to the test station from the tap. A ball valve was placed before the test station which allowed for fine control of the water flow rate. The water flowed through the test section, made of polyethylene tubing (shown as "length L" in Fig. 1), and was then led to the drain for disposal. On either side of the test section were push-to-connect tee fittings that connected the flow to PVC tubing open to the surroundings. This tubing was fixed to retort stands with tie wraps and used as piezometer tubes to measure the difference in fluid pressure across the test section. The volumetric flow rate of the water was measured by timing how long it took to collect a given volume of water in a graduated cylinder.

Because the push-to-connect fittings are nonpermanent, changes can easily be made to the test section. For example, different lengths of tubing can be used and various fittings, such as elbows or valves, can be included.

By applying the Bernoulli equation between the two points where the pressure is measured and estimating friction losses, the predicted pressure difference can be calculated and compared to values measured experimentally. Friction losses through pipe lengths can be estimated using the Moody plot or applicable correlations, and friction losses through the fittings can be calculated using published loss coefficients.

2.1.1 Objectives. The students were asked to devise a lab experiment that involved the measurement of friction losses through various pipe lengths and fittings that could be compared to predictions using calculation methods demonstrated in class.

2.1.2 Materials. Students were supplied with the following parts to build the experiment: 2.5 feet of PVC tubing ( $1 / 4$ " ID and $1 / 2$ " OD); 2.5 feet of PVC tubing $(1 / 4 "$ ID and $3 / 8$ " OD); 10 feet of polyethylene tubing ( $3 / 8$ " ID 
and $1 / 2 "$ OD); 5 feet of polyethylene tubing ( $1 / 4^{\prime \prime}$ ID and $3 / 8$ " OD); two push-to-connect tee fittings for $1 / 2$ " tube OD; two push-to-connect tee fittings for $3 / 8$ " tube OD; two push-to-connect $90^{\circ}$ elbows for $1 / 2$ " tube OD; one pushto-connect straight connector for $3 / 8 "$ x $1 / 2$ " tube OD; one push-to-connect ball valve for $1 / 2$ " tube OD.

\subsection{Falling Sphere Viscometer}

When an object, such as a sphere, is allowed to fall through a fluid medium by gravity, the fluid imparts a resistive frictional force on the object. This resistive force, referred to as the drag force, is given by:

$$
F=\frac{1}{2} \rho u^{2} C_{d} A
$$

where $\rho$ is the fluid density, $A$ is the cross sectional area, and $u$ is the velocity of the falling particle. The drag coefficient, $C_{d}$, depends on the particle Reynolds number, which in turn depends on the fluid density and viscosity as well as the diameter and velocity of the falling sphere. Knowing the density and volume of the sphere, a force balance can be applied to the falling sphere to estimate its terminal velocity. Because the value of $C_{d}$ depends on velocity, this becomes an iterative calculation. However, at low Reynold numbers, which occurs when the fluid viscosity is large or the particle diameter is small, $C_{d}$ is proportional to the inverse of the Reynolds number and the calculation of velocity simplifies significantly. In this situation, the system is said to follow Stokes' law, and fluids with sufficient viscosity can be used to ensure that the experiment operates in this range.

By calculating the predicted velocity and comparing it to the velocity measured experimentally, the effectiveness of the falling sphere viscometer can be determined.

2.2.1 Objectives. The students were asked to create a device for measuring the viscosity of a fluid and devise a procedure that validates the effectiveness of the device using fluids of known viscosity.

2.2.2 Materials. Figure 2 shows the experimental setup for the falling sphere viscometer. The viscometer was constructed using clear PVC pipe of $3 / 8$ " or $1 / 2$ " diameter. A threaded adapter was glued on either end of the pipe to allow a cap to be screwed on for easy access. The pipe was clamped vertically to a retort stand.

The following viscosity standards from Cannon Instrument Company ${ }^{\circledR}$ were used: S200, N350 and S600, which have viscosities of 460,830 and $1500 \mathrm{cP}$ at $20^{\circ} \mathrm{C}$, respectively. These high viscosity fluids ensured the applicability of Stokes' law. The following spheres were available to the students for testing: glass (diameters of $3 / 32^{\prime \prime}, 1 / 8$ ", and $1 / 4 "$ ), aluminum (diameters of $3 / 32$ " and $1 / 8 "$ ), and stainless steel (diameters of $3 / 32$ ", $1 / 8$ ", $1 / 4$ ", and $7 / 6 "$ ).

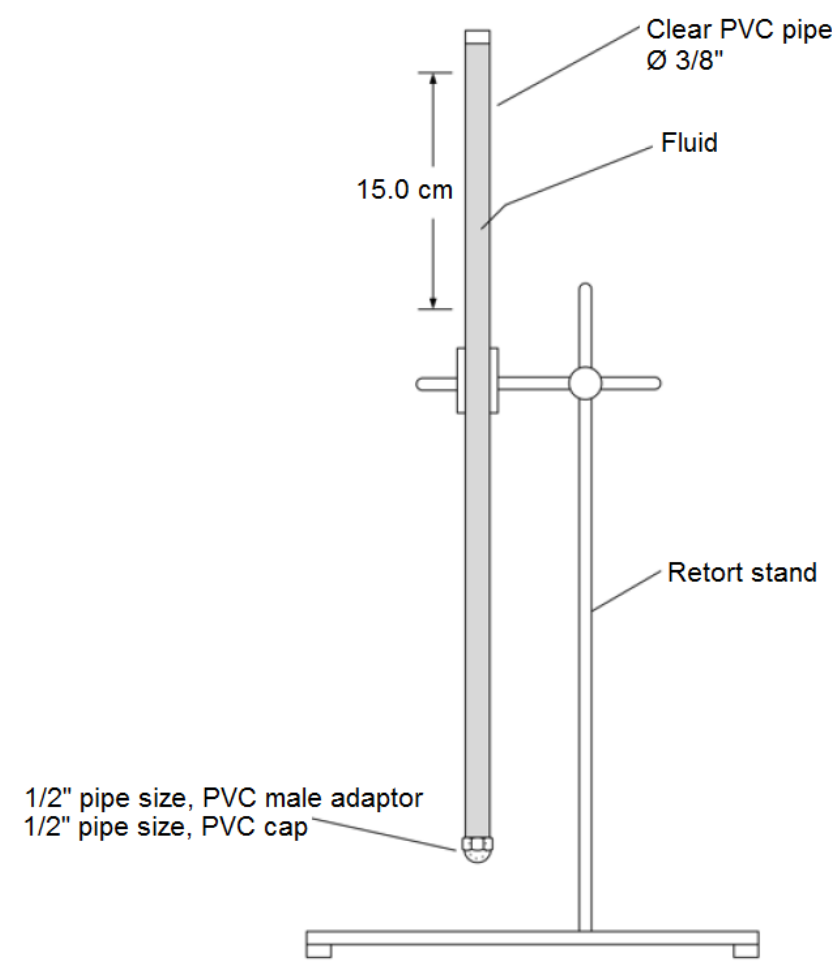

Fig. 2. Falling sphere viscometer experiment (drawing created by one of the student groups).

\subsection{Torricelli's Tank}

Evangelista Torricelli (1608-1647) related the velocity of a liquid flowing out of an opening from a container $(u)$ to the height of liquid above the opening $(h)$ :

$$
u=\sqrt{2 g h}
$$

Torricelli developed the equation before Daniel Bernoulli's (1700-1782) famous principle, and it was later shown to be a special case of the latter.

The experimental setup, shown in Fig. 3, was used to demonstrate Torricelli's principle. It involved a pail that had been modified to include two outlet holes, one above the other. A quick-disconnect socket fitting with a shutoff valve was used to plug the holes when the experiment was not in use. To unplug the hole, the quick-disconnect fitting plug was inserted. To maintain a constant liquid level, a drain hole was made near the top of the pail. Tap water was allowed to flow continuously into the pail. The velocity of the water stream leaving the outlet hole was calculated by measuring the volumetric flow rate using a graduated cylinder and stopwatch, and using the diameter of the outlet hole. Under these steady-state conditions, the expected velocity was calculated using Torricelli's equation and compared to the measured velocity.

The use of the quick-disconnect fitting resulted in significant friction losses and large differences in the values since Torricelli's equation does not include friction losses. This created an opportunity to use the 
experimental results to calculate the loss coefficient of the fitting.

The second part of the experiment was to time how long it took for the liquid level in the pail to drop a certain height. Assuming constant density and neglecting friction losses, the law of conservation of mass can be used to derive the following equation:

$$
\Delta t=\frac{-2}{\sqrt{2 g}}\left(\frac{D_{1}}{D_{2}}\right)^{2}\left(\sqrt{h_{2}}-\sqrt{h_{1}}\right)
$$

where $h_{1}$ and $h_{2}$ are the initial and final liquid heights above the exit hole, respectively, $\Delta t$ is the time is takes the liquid level to fall from $h_{1}$ to $h_{2}$, and $D_{1}$ and $D_{2}$ are the diameters of the pail and the exit hole, respectively.

The liquid level was measured experimentally as a function of time, and these results were compared to the predicted trend. Equation (3) does not include friction losses at the outlet hole, however the loss coefficient determined from the first part of the experiment can be included in the derivation to improve the accuracy of the predictions.

2.3.2 Objectives. The students were asked to create a device and procedure that demonstrates Toricelli's equation in two ways. First, by showing that the velocity of the exiting water stream is related to the liquid level above the exit by Torricelli's equation. The second demonstration was to use the device to time how long it will take the tank to drain and compare this result to the prediction from Torricelli's equation.

2.3.1 Materials. The students were supplied with the following materials: one 2-gallon plastic pail; one nylon barbed tube fitting for $1 / 2$ " tube ID with $1 / 8$ " male threading; 5 feet of PVC tubing ( $1 / 2$ " ID and $5 / 8$ " OD) for the drain line; two quick-disconnect tube coupling sockets with shut-off valve $(1 / 8$ " coupling and $1 / 8$ " male NPT); two quick-disconnect tube coupling plugs without valve $(1 / 8$ " coupling for $1 / 8$ " tube ID); and one adhesive-back ruler for measuring liquid level.

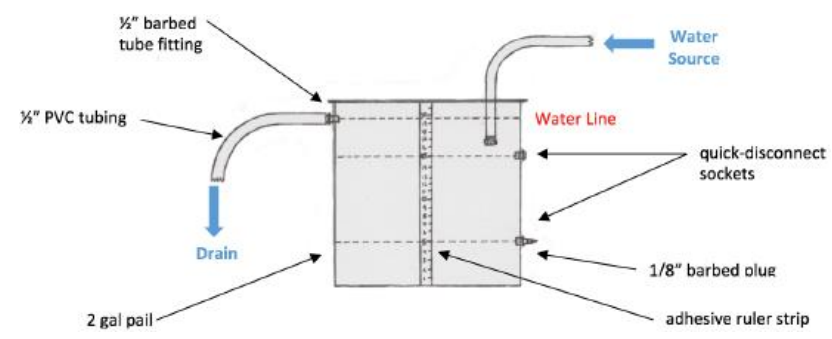

Fig. 3. Torricelli's tank experiment (drawing created by one of the student groups).

\section{RESULTS}

In general, students brought a good level of enthusiasm to the project. Most groups calculated the basic data that could be obtained from the lab experiment. However, there were some instances of additional creativity.

The friction losses experiment allowed for the greatest degree of creativity. Each group usually chose one or two arrangements to focus on. Some looked at the effects of changing the length of pipe, the effect of including elbows, or including a valve. The experimental setup could also easily be modified to include changes in elevation between the two points, as shown in Fig. 4.

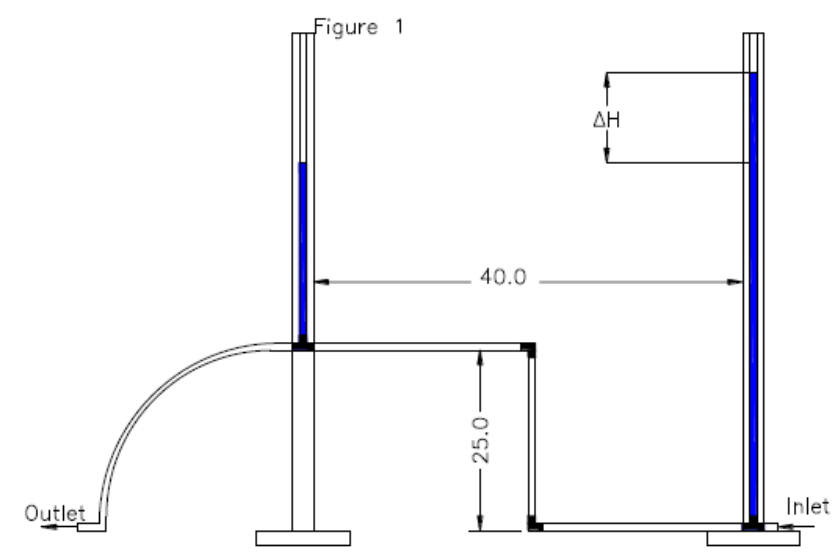

Fig. 4. Example of the friction losses experimental setup including a change in elevation (drawing created by one of the student groups).

For the falling sphere viscometer, most groups focused on studying the effect of changing particle diameter and density on terminal velocity. The viscous nature of the fluids made it difficult to switch fluids between trials. Most groups focused on calculating the percentage error between the calculated and measured velocities and discussing the trends and experimental error. A few groups developed a procedure for measuring the drag coefficient $\left(C_{d}\right)$ as a function of Reynolds number to verify that it followed the expected trend at low Reynolds numbers.

For the Torricelli's tank experiment, it was clear right away to the students that there were significant friction losses through the quick-disconnect fitting. Groups approached this problem in different ways. Some groups opted to present only a qualitative discussion of why the results were different from the ideal Torricelli's equation. Other groups removed the fitting and modified the Torricelli equation to include contraction and expansion losses when calculating the expected velocities. Another approach was to keep the valve and use the results to estimate its loss coefficient. 


\section{CONCLUSION}

The open-ended lab exercise provided a means of introducing some aspects of design to an introductory course while still maintaining a reasonable workload balance for the students. There are numerous benefits to an open-ended lab design project for both the students and the course instructor.

Although the project is not a standard open-ended design project, there are many similarities. For example, students must perform preliminary calculations in the planning stage, they must assemble the parts into a working unit, and must execute and validate the data obtained. Further, students have the opportunity to incorporate creativity into their project, a quality that is more in line with a design project rather than a standard lab activity.

It was also observed that students were quite thoughtful about the educational merit of their lab procedure. The discussions students had with the instructor often began with comments like "We think that the students will learn more if they conduct the lab this way". This shows that the students were thoughtfully considering the main objectives of the project in their final design, an important feature of a well-designed product or process. Also, since students can gain a deeper understanding of a subject when they teach it to others [6], having the students approach this project with this attitude may have helped them learn the material for themselves.

Another benefit of open-ended projects is that they allow students to work within their own abilities. A good portion of the groups were satisfied to complete a basic experimental setup that successfully collected the expected data. This approach would generally receive a "meets expectations" grade, depending on how well this was completed and presented. However, as mentioned in the discussion, some students challenged themselves to be more creative when designing their lab procedure. It is therefore a good way to reach out to the entirety of the class and cater to students with a wide range of abilities.

The other benefits are the obvious links to course material, as well as some experience with hands-on building and use of hand tools. However, apart from using a power drill to create holes in the pail for the Torricelli's tank experiment, this was minimal in these particular projects.

The course instructor can benefit from a project like this as it provides an opportunity to test potential lab experiments that can be implemented in the future. The students will perform most of the troubleshooting and develop useful written documents that can be adapted into lab procedures. The students may even come up with creative procedures and ideas that the instructor may not have thought of if developing the lab on their own.

The challenge students face in this type of open-ended course project is that it may interfere with the time they put into studying the concepts covered in the class. The challenges for the instructor are the additional time for selecting and ordering parts for the project.

The other challenge is the effective evaluation of the final report, since most of these introductory classes tend to have a high enrollment. Report guidelines must be clear and kept minimal to ensure that the instructor has enough time to effectively review all of the reports. If multiple teaching assistants are reviewing the reports, rubrics must be developed to assure consistent evaluation and provide students with valuable feedback.

\section{Acknowledgements}

Financial support from Dalhousie's Faculty of Engineering and the Shell Experiential Learning Fund (SELF) is gratefully acknowledged. We would also like to thank the students of ENGI 2102 from fall 2015 for their participation in the project.

\section{References}

[1] Lyle D. Feisel and Albert J. Rosa, "The Role of the Laboratory in Undergraduate Engineering Education," $J$. Eng. Educ., vol. 94, no. 1, pp. 121-130, 2005.

[2] Romanas V. Krivickas and Jonas Krivickas, "Laboratory Instruction in Engineering Education," Global J. of Engng. Educ., vol. 11, no. 2, pp. 191-196, 2007.

[3] Eric B. Ratts, "Thermal-Fluids Laboratory Project: First and Second Law Analysis of a Thermoelectric Cooler," Int. J. Engng Ed., vol. 16, no. 6, pp. 529-533, 2000.

[4] Michele Hastie and Jan Haelssig, "Short Design Projects for an Introductory Thermofluids Engineering Course," in Proc. CEEA Canadian Engineering Education Conf., CEEA15, Andy Fisher (ed.) (Hamilton, ON; 31 May - 3 June 2015), 6 pp., 2015.

[5] Thomas Fuhrmann, Roland Mandl, and Mikhail Shamonin, "Analysis of learning improvement on changing lab course from single experiments to projects," Int. J. Elec. Eng. Educ., vol. 52, no. 4, pp. 287-297, October 2015.

[6] Richard M. Felder and Rebecca Brent, "Learning By Doing," Chem. Eng. Educ., vol 37, no. 4, pp. 282-283, 2003. 